MACROPHAGES harvested from the peritoneal cavities of rats release a neutrophil chemotactic factor (MNCF) in response to stimulation with Gram-negative bacterial lipopolysaccharide (LPS). MNCF has been shown to be active in rats treated with dexamethasone, a glucocorticoid that usually inhibits the neutrophil migration induced in this species by interleukin (IL)-1, tumour necrosis factor alpha (TNF $\alpha)$, IL-8, C5a and leukotriene $B_{4}$ $\left(\mathrm{LTB}_{4}\right)$. Here we report that macrophages harvested from peritoneal cavities of mice, and stimulated in vitro with LPS, also release a factor that induces neutrophil migration in dexamethasone-treated animals. This chemotactic activity was neutralized by the incubation of the LPSstimulated macrophage supernatants with a purified polyclonal IgG anti-mouse TNF $\alpha$. In addition, significant amounts of TNF were detected in the supernatants. The neutrophil migration induced by intraperitoneal administration of recombinant murine TNF $\alpha$ was also unaffected by pretreatment of the mice with dexamethasone. Moreover, neutrophil migration induced by intraperitoneal injection of LPS was completely blocked by pretreatment of the mice with a monoclonal antibody against murine $T N F \alpha$. In conclusion, our results support the hypothesis that, in contrast to the role of TNF in rats (where it indirectly induces neutrophil migration), in mice, it may be an important mediator in the recruitment of neutrophils to inflammatory sites.

Key words: Glucocorticoids, Neutrophil migration, Tumour necrosis factor alpha

\section{The neutrophil migration induced by tumour necrosis factor alpha in mice is unaffected by glucocorticoids}

\author{
C. A. Cecilio, ${ }^{1}$ E. H. Costa, ${ }^{1}$ P. Ucelli, ${ }^{1}$ \\ C. A. A. Chaves, ${ }^{1}$ M. C. Toffoli, ${ }^{2}$ C. A. Flores, ${ }^{3}$ \\ F. O. Cunha, ${ }^{4}$ S. H. Ferreira ${ }^{4}$ and \\ W. M. S. C. Tamashiro ${ }^{1, C A}$
}

\begin{abstract}
1Department of Microbiology and Immunology, Institute of Biology, UNICAMP, 13081-970, Campinas, SP, Brazil; ${ }^{2}$ Department of Pharmacology, Faculty of Medicine, UNICAMP, 13081-970, Campinas, SP, Brazil; ${ }^{3}$ Department of Pharmacology, Faculty of Medicine, UFCE, 60001-970, Fortaleza, CE, Brazil; ${ }^{4}$ Department of Pharmacology, Faculty of Medicine of Ribeirão Preto, USP, 14049 Ribeirão Preto, SP, Brazil
\end{abstract}

${ }^{\mathrm{CA}}$ Corresponding Author Fax: $(+55) 192393124$

\section{Introduction}

Neutrophil migration is a key event in acute inflammatory reactions. This is a complex and multimediated event and remains not completely understood. Chemotactic mediators are generally derived either from plasma components or from multiple cellular sources, ${ }^{1,2}$ and one of the most important cellular sources of neutrophil chemotactic factors is resident macrophages. ${ }^{1,3}$ In fact, it has been shown that neutrophil migration into the peritoneal cavity, induced by carrageenin, endotoxin, latex beads or zymozan, is increased when the number of resident macrophages is augmented by pretreatment with thioglycollate, and reduced after depletion of the peritoneal macrophage population through previous washing of the cavity.

The chemotactic mediators thought to be involved in neutrophil migration into inflamed tissues include the fifth complement component fragment, C5a, leukotriene B4 $\left(\mathrm{LTB}_{4}\right){ }^{6}{ }_{7}^{6}$ and the pleitropic cytokines interleukin (IL)-1, tumour necrosis factor alpha (TNF $\alpha){ }^{7}$ and IL-8. ${ }^{8}$ Some of these substances, such as C5a, may have a direct chemotactic effect on neutrophils; $5^{5}$ others may act indirectly through mechanisms which depend upon the resident cells of the tissues, and the endothelium. ${ }^{7,8}$ IL-1, TNF and $\mathrm{LTB}_{4}$, for example, not only increase the expression of adhesion molecules but also stimulate the release of chemotactic factors by rat resident macrophages. Furthermore, neutrophil migration into the peritoneal cavities of rats induced by these substances is also dependent on the number of resident macrophages. ${ }^{7}$ Another potent leukocyte chemoattractant cytokine is IL-8, which has been shown to induce neutrophil migration by means of a mast cell dependent mechanism, since its activity cannot 
be observed in rat peritoneal cavities depleted of mast cells or in mice lacking this cellular population. ${ }^{8}$ Furthermore, rat mast cells stimulated with IL-8 release a neutrophil chemotactic activity into the supernatant. ${ }^{8}$

It has been demonstrated that macrophages incubated in vitro with either LPS 3 or IL-1 and $\mathrm{TNF}^{7}$ release a neutrophil chemotactic factor named MNCF (macrophage-derived neutrophil chemotactic factor) into the supernatant. This factor has a mol.wt of $54 \mathrm{kDa}$, a $\mathrm{PI}<4.0$ and lectin-like activity.? The neutrophil migration induced by MNCF in rats is unaffected by the variation of the number of resident peritoneal cells, as well as by pretreatment of animals with glucocorticoids. Based upon these results, it was suggested that $\mathrm{MNCF}$ may be a mediator involved in the recruitment of neutrophil induced by various inflammatory stimuli, such as the cytokines IL-1 and TNF $\alpha$ in rats.

The fact that the glucocorticoids did not affect MNCF-induced neutrophil migration conflicts with the hypothesis that glucocorticoids block the expression of adhesion molecules in the neutrophil and endothelium. ${ }^{10}$ It thus seems reasonable to speculate that certain stimuli, such as MNCF, can by-pass one or more critical steps which are sensitive to glucocorticoids, inducing leukocyte migration, whereas other stimuli, even though capable of by-passing some of these steps, cannot cause in vivo neutrophil migration in glucocorticoid-treated animals. Thus, it has been shown that in the hamster chick-pouch model of inflammation, dexamethasone failed to block the $\mathrm{LTB}_{4}$-induced neutrophil adherence to and migration through endothelial cells. ${ }^{11}$ In this model the neutrophils were halted in the lamina basal, between the endothelial cells and the pericyte, never reaching the intersticial space.

The present study shows that LPS-stimulated mouse macrophage monolayers release an MNCFlike mediator into culture supernatants since these supernatants induced neutrophil migration into the peritoneal cavities of animals pretreated with dexamethasone. Not only were significant amounts of $\mathrm{TNF} \alpha$ deteted in the supernatants, but their in vivo neutrophil chemotactic activity was also neutralized by preincubation with a purified polyclonal IgG anti-mouse TNFo. Furthermore, the neutrophil recruitment induced by the intraperitoneal administration of recombinant murine $\mathrm{TNF} \alpha$ was not affected by the treatment of the mice with dexamethasone. A monoclonal antibody against TNF was also shown to be able to block the LPS-induced neutrophil migration to the peritoneal cavities of mice completely.

\section{Materials and Methods}

\section{Reagents}

LPS isolated from Escherichia coli O111B4 was purchased from Sigma (St Louis, MO). Recombinant murine TNF $\alpha(\mathrm{rmTNF} \alpha)$ was donated by Dr M. A. Palladino (Genentech Inc., South San Francisco, CA). The rat monoclonal antibody against rmTNFa (XT22.11) was purified from mice ascitic peritoneal fluids by affinity chromatography on Sepharose-protein G (Sigma).

\section{Animals}

Male 8- to 10-week-old C57BL/6 mice (Centro Multinstitucional de Bioterismo-CEMB/UNICAMP, Campinas, SP, Brazil) were housed in a temperature-controlled room and received water and food ad libitum throughout the period of study.

\section{Preparation of anti-TNF sera}

Polyclonal rabbit antisera against recombinant murine TNF $\alpha$ were produced in New Zealand rabbits, as described elsewhere. ${ }^{12}$ Briefly, on day $0,100 \mu \mathrm{g}$ of rmTNF $\alpha$ were diluted in $500 \mu \mathrm{l}$ of a phosphate buffered saline solution (PBS) and mixed with an equal volume of Freund's complete adjuvant, and the emulsion was injected intradermically into the rabbits. Boosting with intradermal injections of emulsions containing 50,10 , and $10 \mu \mathrm{g}$ of rmTNF, in $50 \%$ Freund's incomplete adjuvant, occurred on days 15,30 and 45 , respectively. The rabbits were bled 10 days after the final injection. Specific antibodies against TNF present in the sera were detected by immunoblotting and capacity to block the effect of TNF on WEHI cells. In some experiments, antibodies obtained by chromatography of the sera in DEAE-Sepharose, according to the manufacturer's recommendations, were used as an $\operatorname{IgG}$ fraction.

\section{LPS stimulated murine macrophage supernatants}

Mouse peritoneal cavities were stimulated by the injection of a $3 \%$ thioglycollate solution (DIFCO Laboratories; Detroit, MI) (3 ml/animal). Four days later, the peritoneal cells were harvested with RPMI 1640 (Flow Laboratories, McLean, VA) and seeded on plastic tissue culture dishes at a density of $2 \times 10^{6}$ cells $/ 5 \mathrm{ml} /$ plate. The cells were allowed to adhere for $1 \mathrm{~h}$ at $37^{\circ} \mathrm{C}$ in an atmosphere of air with $5 \% \mathrm{CO}_{2}$. Adherent cells (95\% macrophages) were washed 
three times with PBS ( $\mathrm{pH} 7.2$ ), and incubated for $30 \mathrm{~min}$ with $5 \mathrm{mg} / \mathrm{ml}$ of LPS in RPMI or with RPMI alone. The supernatants were discarded and the cells were extensively washed with PBS, followed by a final $2 \mathrm{~h}$ incubation at $37^{\circ} \mathrm{C}$ with $5 \mathrm{ml}$ of RPMI medium per dish (without LPS or fetal calf serum). The cell-free incubation fluids were subsequently ultradiafiltered through a YM 10 membrane with a cutoff $10 \mathrm{Kd}$ (Amicon Corp., Lexington, MA, USA). The final volumes (corresponding to $5 \%$ of the original volume) were filtered on $0.22 \mu \mathrm{m}$ membranes (Millipore; Bedford, MA) and the samples were kept at $-70^{\circ} \mathrm{C}$ for TNF detection and neutrophil migration assays.

\section{Detection of TNF in the supernatants}

The TNF content in macrophage supernatants was measured using a highly TNF-sensitive cell line, WEHI 164 clone 13, as described elsewhere. ${ }^{13}$ Briefly, WEHI cells were seeded on microplates (Costar 3596, Cambridge, MA) at a density of $4 \times 10^{4}$ cells/well in $50 \mu$ lof growth medium (RPMI 1640 medium containing 10\% fetal calf serum (Gibco)). Fifty $\mu \mathrm{l}$ of diluted supernatants were added to the cells, and the experiments were conducted in triplicate. The plates were incubated for $20 \mathrm{~h}$ at $37^{\circ} \mathrm{C}$ in a $5 \% \mathrm{CO}_{2}$ incubator; $10 \mu \mathrm{l}$ of a 34,5 -dimethylthiazol-2-1-3,5-diphenylformazan solution $(5 \mathrm{mg} /$ $\mathrm{ml}$ PBS) (MTT, Sigma) were added to each well and the plates incubated for an additional $4 \mathrm{~h}$. One hundred $\mu \mathrm{l}$ of isopropanol containing $0.04 \mathrm{~N} \mathrm{HCl}$ were added to each well. Fifteen min later, the degree of cell lysis was determined spectrophotometrically $(570 \mathrm{~nm})$ using an enzyme-linked immunoassay analyser (Multiskan MCC/340 MKII, Flow Laboratories). TNF content in the assayed materials was calculated by comparison with standard curves which were determined with rmTNF (Genentech Inc.). The results correspond to the averages obtained in at least three independent experiments.

The presence of the TNF in the supernatants was confirmed by ELISA assays using the monoclonal antibody against TNF (XT 22.11) as the coating antibody $(10 \mu \mathrm{g} / \mathrm{ml})$ and the rabbit polyclonal antibodies (serum dilution 1:200) as the detecting antibody. The bound rabbit antibodies were revealed using an immunoperoxidase conjugate anti-rabbit IgG, and the chromogenic substrat OPD (Sigma). In our system, it was possible to detect amounts of TNF varying between 50 to $0.25 \mathrm{ng} / \mathrm{ml}$, according to standard curves performed with mrTNFo.

\section{In vivo neutrophil migration}

The method for testing in vivo neutrophil migration has been described elsewhere. ${ }^{3}$ Briefly, LPS solutions $(8-1000 \mathrm{ng} / 0.2 \mathrm{ml}$ of saline solution/animal), rmTNFo $(10-100 \mu \mathrm{g} /$ $0.2 \mathrm{ml} /$ animal) and either LPS-stimulated or nonstimulated macrophage supernatants (equivalent to the products released by $2 \times 10^{6}$ adherent cells $/ 0.2 \mathrm{ml} / \mathrm{animal}$ ) were injected into the peritoneal cavities of mice pretreated subcutaneously (s.c.) with dexamethasone $(0.5 \mathrm{mg} / \mathrm{kg})$ $1 \mathrm{~h}$ previously. Controls received intraperitoneal (i.p.) injections of sterile saline solution. Six hours after these i.p. injections, the mice were sacrificed in a $\mathrm{CO}_{2}$ chamber, and their peritoneal cavities washed with $3 \mathrm{ml}$ of PBS containing $5 \mathrm{IU} / \mathrm{ml}$ of heparin; total and differential cell counts in the washing fluid were conducted as described elsewhere. ${ }^{9}$ The results are expressed as means \pm standard error of the mean (SEM) for the number of neutrophils per $\mathrm{ml}$ of peritoneal wash.

In some experiments, rmTNF $\alpha$ was incubated for $30 \mathrm{~min}$ at $37^{\circ} \mathrm{C}$ with polyclonal $\mathrm{IgG}$ anti-TNF $(100 \mu \mathrm{ggG} / 100 \mathrm{ng} \mathrm{TNF})$ prior to the i.p. injections. The control groups for these experiments received i.p. injections of the same quantity of the antibody diluted in saline solution.

In other experiments, monoclonal antibody against TNF (XT22.11) was administrated intraperitoneally to mice $(100 \mu \mathrm{g} /$ cavity) $1 \mathrm{~h}$ before the i.p. injections of saline solution $(0.2 \mathrm{ml} /$ cavity) or LPS ( $200 \mathrm{ng} /$ cavity), with control group receiving i.p. injections of saline solution prior to the inflammatory stimulus.

\section{Protein measurement}

The protein contents of purified materials was determined according to the method of Hartree. ${ }^{15}$

\section{Statistical analysis}

The data are presented as the means \pm SEM, with statistical comparisons between the groups performed using the Student $t$-test for unpaired samples.

\section{Results}

Time course and dose dependence of LPS-induced neutrophil migration in mice

The intraperitoneal injection of increasing doses of LPS in naive mice induced a dose-dependent neutrophil migration with a bell-shaped curve 
(Fig. 1A). The maximal migration was observed with a dose of $200 \mathrm{ng}$ LPS/cavity, peaking between 8 and $12 \mathrm{~h}$ after the LPS administration, and returning to control levels after $48 \mathrm{~h}$ (Fig. $1 \mathrm{~B})$; the neutrophil migration induced by the dose of $1000 \mathrm{ng} /$ cavity was less than that observed with the other doses tested.

\section{Effects of dexamethasone \\ pretreatment of mice and pre- \\ incubation of the LPS-stimulated \\ macrophage supernatants with TNF \\ specific antibodies on capacity to \\ induce neutrophil migration}

The supernatants from LPS-stimulated macrophages induced a significant neutrophil migration into the peritoneal cavities of naive mice, which was not significantly inhibited by the pretreatment of the animals with dexamethasone (Fig. 2A). The dexamethasone treatment, however, reduced the neutrophil migration induced by saline solution. On the other hand, the pre-incubation of these supernatants (from $2 \times 10^{6}$ adherent cells) with the $\mathrm{IgG}$ fraction of anti-rmTNFo serum $(100 \mu \mathrm{g})$ eliminated their capacity to induce neutrophil migration into peritoneal cavities of dexamethasone-pretreated mice (Fig. 2B). The same quantity of IgG did not interfere with neutrophil migration in the control group.

\section{TNF concentration in the LPS-} stimulated macrophage supernatants

The TNF concentration for five different samples of LPS-stimulated macrophage super-

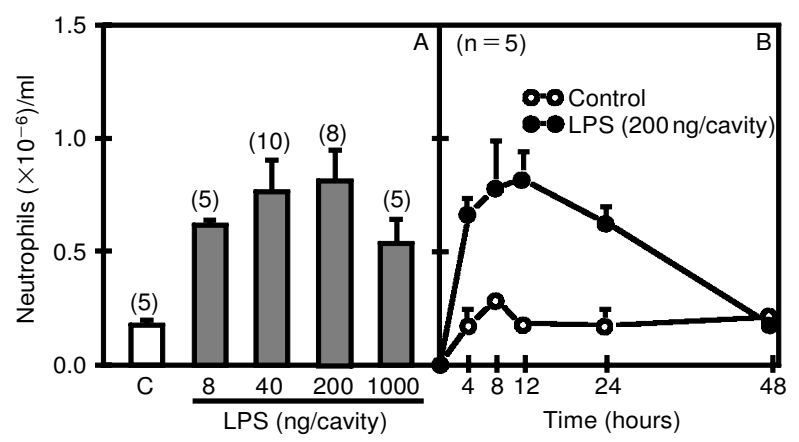

FIG. 1. Dose response and time course of neutrophil migration induced by LPS. (A) Bars represent neutrophil migration induced by the indicated doses of LPS into peritoneal cavities of mice. The control (C) represents neutrophil migration induced by saline solution. The neutrophil migration was analysed $6 \mathrm{~h}$ after the injection of the stimuli. The number of animals per experimental group is indicated at the top of the bars. (B) Time course of neutrophil migration induced by either LPS (200 ng/cavity) or saline solution (control group). The number of animals per group was five. In both panels, the results are reported as mean \pm SEM.

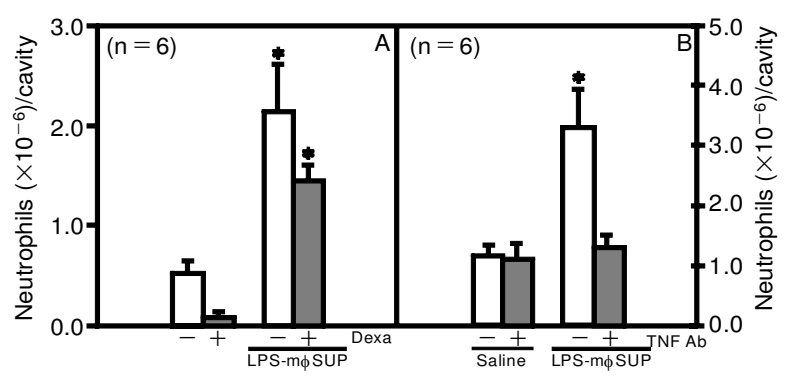

FIG. 2. Effects of dexamethasone pretreatment and preincubation of LPS-stimulated mouse macrophage supernatants with specific antibody to rmTNF $\alpha$ on capacity to induce neutrophil migration. (A) Bars represent neutrophil migration induced by saline solution or LPS-stimulated mouse macrophage supernatants (LPS-M $\phi$ SUP) into peritoneal cavities of mice, pretreated $(+$, hatched bars) or not (-, open bars) with dexamethasone (Dexa). (B) Bars represent neutrophil migration induced by LPS-M $\phi$ SUP, incubated $(+)$ or not (-) with $100 \mu \mathrm{g}$ of IgG anti-rmTNF $\alpha$, into peritoneal cavities of dexamethasone-pretreated mice. Control groups received i.p. injections of saline solution or saline solution containing IgG anti-TNF $\alpha(100 \mu \mathrm{g} / 0.2 \mathrm{ml} / \mathrm{ani}$ mal). In both panels, the results are reported as mean \pm SEM for six animals in the group. ${ }^{*} \mathrm{P}<0.05$ (Student's $\mathrm{t}$ test).

natants, derived from the culture of $2 \times 10^{5}$ adherent cells, varied from 1 to $14 \mathrm{ng}$ as detected by activity and/or ELISA assays.

\section{Effect of dexamethasone}

pretreatment on neutrophil migration

induced by recombinant murine

$\mathrm{TNF} \alpha$ in mice

The intraperitoneal administration of $\mathrm{rmTNF} \alpha$ in naive mice induced a dose-dependent neutrophil migration which peaked $5-10 \mathrm{~h}$ after the injection. In dexamethasone-pretreated mice, rmTNF $\alpha$ also induced a dose-dependent neutrophil migration, which was determined $6 \mathrm{~h}$ later; the migration induced by a dose of $0.1 \mu \mathrm{g} \mathrm{TNF} /$ cavity in naive mice was similar to that observed for dexamethasone-pretreated animals (Fig. 3A). Fig. 3B shows that the neutrophil chemotactic activity of the rmTNF $\alpha$ was completely eliminated by pre-incubation with an anti-TNF $\alpha$ IgG.

\section{Effect of treatment with}

dexamethasone or TNF specific antibody on LPS-induced neutrophil migration in mice

The intraperitoneal injection of LPS in naive mice induced significant neutrophil migration which was suppressed by pretreatment with dexamethasone (Fig. 4A). This LPS-induced neutrophil migration was completely eliminated by pretreatment of the animals with a monoclonal antibody against TNF $\alpha$ (Fig. 4B). 


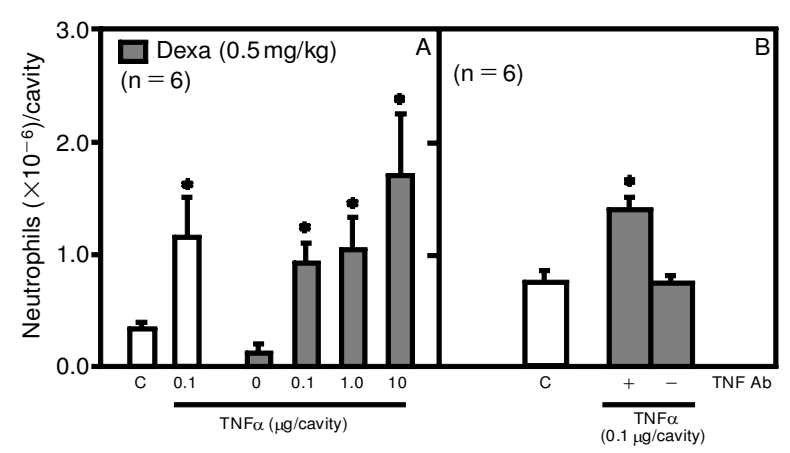

FIG. 3. Effect of dexamethasone pretreatment on the neutrophil migration induced by rmTNF $\alpha$ in mice. (A) Bars represent neutrophil migration induced i.p. injection of saline solution (SAL) or of the indicated amounts (in $\mu \mathrm{g}$ animal) of rmTNF $\alpha$ into peritoneal cavities of dexamethasone-pretreated or naive mice (hatched and open bars, respectively). (B) Bars represent neutrophil migration induced by $0.1 \mu \mathrm{g} \mathrm{rmTNF} \alpha$, preincubated (+) or not (-) with $100 \mu \mathrm{g}$ of $\operatorname{lgG}$ anti-TNF $\alpha$, into peritoneal cavities of dexamethasone-pretreated mice. The control animals (SAL) received i.p. injections of saline solution containing $\mathrm{IgG}$ anti-TNF $\alpha(100 \mu \mathrm{g} / 0.2 \mathrm{ml} /$ animal). In both panels, the results are reported as means \pm SEM for six animals in the group. *P $<0.05$ (Student's t-test).

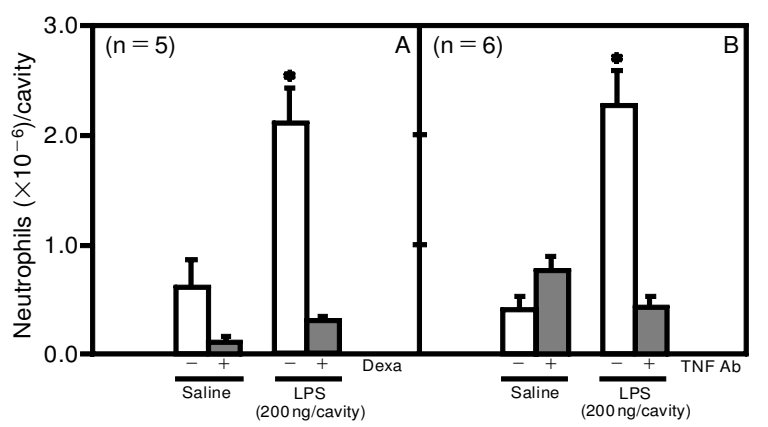

FIG. 4. Effects of pretreatment of mice with either dexamethasone or monoclonal antibody against murine TNF $\alpha$ on neutrophil migration induced by LPS. (A) Bars represent neutrophil migration induced by i.p. injection of saline solution $(0.2 \mathrm{ml} /$ cavity) or of LPS ( $200 \mathrm{ng} /$ cavity) in dexamethasone-pretreated or non-treated mice $(+$, hatched and -, open bars, respectively). (B) Bars represent neutrophil migration induced by saline solution $(0.2 \mathrm{ml} / \mathrm{animal})$ or by LPS (200 ng/animal) into peritoneal cavities of mice either pretreated $(+$, hatched bars) or not $(-$, open bars) with monoclonal antibody against TNF $\alpha(100 \mu \mathrm{g} /$ animal). In both panels, the results are reported as means \pm SEM for five animals in the group. 'P $<0.05$ (Student's t-test).

\section{Discussion}

The intraperitoneal injection of LPS in mice caused a significant, dose and time-dependent, neutrophil migration with a bell-shaped doseresponse curve, as was found in other species. ${ }^{16,17}$ This may be due to the liposolubility of the LPS and the fact that when it is injected in high concentrations into extravascular tissue, the amount that enters the circulatory system is sufficient to block neutrophil migration. It has, for example, been demonstrated that intravenous administration of LPS inhibits the neutrophil migration induced by various stimuli, including LPS itself. ${ }^{16}$ It has recently been demonstrated that macrophages harvested from the peritoneal cavities of rats and stimulated in vitro with LPS release MNCF, a neutrophil chemotactic factor. ${ }^{18}$ Rat macrophages stimulated in vitro with IL-1 and TNF also release MNCF? The neutrophil migration induced by such MNCF is unaffected by the number of resident cells or by the treatment of the rats with dexamethasone. ${ }^{19}$ The fact that this glucocorticoid did not affect the neutrophil migration induced by MNCF made the factor distinguishable from the other known neutrophil chemotactic mediators, since it has been demonstrated that the neutrophil migration induced by IL-1, TNF, IL-8, FMLP, C5a and $\mathrm{LTB}_{4}$ in rats is inhibited by treatment with dexamethasone. 7,8 It is thus suggested that in rats MNCF may be a late mediator in the recruitment of neutrophil induced by various stimuli, including the cytokines IL-1 and TNF.

In the present study we demonstrated that macrophages harvested from peritoneal cavities of mice and stimulated with LPS for a brief period of time also released a neutrophil chemotactic factor into the supernatants, and the activity of this factor was not significantly inhibited by pre-treatment of animals with dexamethasone, at least at doses that block the neutrophil migration induced by LPS.

The incubation of the supernatant with an antibody against murine TNF blocked the neutrophil chemotactic activity, thus suggesting that the presence of the TNF was responsible for this activity. This fact also suggested that the neutrophil chemotactic activity of the supernatant was due to the presence of the TNF. The presence of TNF in the supernatant was then confirmed, and dose-dependent neutrophil migration in dexamethasone-treated mice was induced by the intraperitoneal administration of recombinant murine TNF. This neutrophil migration was not statistically different from that observed in untreated mice. The antibody that blocked the neutrophil chemotactic activity of the LPS-stimulated macrophage supernatant also eliminated it for rmTNF. The fact that the quantity of mrTNF necessary to induce neutrophil migration was greater than that found in the supernatant might be explained by the lack of glycosylation in the recombinant form, since it is well established that the level of glycosylation affects the specific activity of this cytokine. These results are in contrast to those obtained in rats, where the neutrophil migration induced by TNF is blocked by pre-treatment with 
dexamethasone; moreover, in this case TNF induces neutrophil migration via $\mathrm{MNCF}^{\text {? }}$

In mice, the TNF generation upon LPS injection was suppressed by in vivo administration of a monoclonal antibody against TNF (XT22.11), which blocked the neutrophil migration induced by the endotoxin. It has recently been demonstrated that TNF is also involved in neutrophil migration into the lung induced by intratracheal challenge of presensitized mice with Schistosom a mansoni egg antigen. ${ }^{20}$

It is well documented that glucocorticoids inhibit the release of several cytokines, including $\mathrm{TNF}^{21-30}$ This fact could explain the inhibitory effect of dexamethasone on the neutrophil migration induced by LPS. The blockage of neutrophilendothelium adhesion has been suggested as a mechanism by which the glucocorticoids inhibit the migration, although in vitro experimental evidences does not support this interpretation. ${ }^{31}$ The in vivo monitoring of different stages of neutrophil migration showed that dexamethasone did not inhibit rolling or adhesion to the venular endothelium induced by $\mathrm{LTB}_{4}$ and $\mathrm{AMLP}$ in hamsters. ${ }^{32}$ Moreover, glucocorticoid treatment did not inhibit neutrophil penetration through the endothelial cell junctions. It was thus concluded that, in addition to the effect of corticoids on the release of chemotactic mediators, they blocked the final step of migration because the neutrophils remained between the endothelium and the basal membrane without reaching the perivascular tissue. ${ }^{32}$ Haptotax is seems to be an important mechanism in this final step, and the binding of the chemoattractant to a sub-endothelial or tissue matrix seems to be an important requirement for the process. In support of this hypothesis, in vitro evidence is provided to show that MNCF and IL-8 are able to induce migration through a haptotatic gradient, although they recognize different ligands. ${ }^{33}$ Since dexamethasone blocks the neutrophil migration induced by IL-8 but does not affect the MNCF activity, it is postulated that glucocorticoids may be able to block the expression of the IL-8 ligand while not affecting that of MNCF. ${ }^{33}$ Thus, TNF probably induces neutrophil migration in mice through a mechanism similar to that described for MNCF in rats, although the expression of the extravascular ligand to TNF in mice is not affected by glucocorticoid treatment. It is important to point out that, despite the fact that $\mathrm{MNCF}$ is not released in significant quantities by mouse macrophages, as demonstrated in the present study, when MNCF from rat macrophages was injected in dexamethasone pretreated mice, the neutrophil migration observed was similar to that observed in normal mice (data not shown).

In conclusion, the results reported here support the hypothesis that, in contrast to rats, in which TNF induces neutrophil migration through an indirect mechanism, in mice TNF may be a late mediator involved in the recruitment of neutrophil into an inflammatory site.

\section{References}

1. Cybulsky MI, McComb DJ, Movat HZ Protein synthesis dependent and independent mechanisms of neutrophil emigration. Different mechanisms of inflammation in rabbits induced by interleukin-1, tumor necrosis factor alpha or endotoxins versus leukocyte chemoattractants. Am J Pathol 1989; 135: 227.

2. Kazmierosky JA, Gallin JI, Reynolds HY. Mechanism of the inflammatory response in primate lungs. Demonstration and partial characterization of an macrophage-derived chemotactic factor with preferential activity on polymorphonuclear leukocytes. J Clin Invest 1977; 59: 273.

3. Gunha FQ, Ferreira SH. The release of a neutrophil chemotactic factor from peritoneal macrophages by endotoxin: inhibition by glucocorticoids. Eur J Pharm acol 1986; 139: 65.

4. Souza GEP, Cunha FQ, Mello R, Ferreira SH Neutrophil migration induced by inflammatory stimuli is reduced by macrophage depletion. Agents and Actions 1988; 24: 377.

5. Yancey KB. Biological properties of human C5a: selected in vitro and in vivo studies. Clin Exp Immunol 1989; 71: 207.

6. MacMillan RT, Foster SJ. Leukotriene B4 and inflammatory diseases. Agents and Actions 1988; 24: 114.

7. Facioli LH, Souza GEP, Cunha FQ, Poole S, Ferreira SH. Recombinant interleukin-1 and tumor necrosis factor induce neutrophil migration 'in vivo' by indirect mechanisms. Agents and Actions 1990; 30: 344.

8. Ribeiro RA, Flores CA, Gunha FQ, Ferreira SH. IL-8 causes in vivo neutrophil migration by a cell-dependent mechanism. Immunology 1991; 73: 472.

9. Dias-Baruffi M, Cunha FQ, Ferreira SH, Roque-Barreira MC. Macrophagereleased neutrophil chemotactic factor (MNCF) induces PMN-neutrophil migration through lectin-like activity. Agents and Actions, 1993; 38: $\mathrm{C} 54-\mathrm{C} 56$.

10. Cronstein BN, Kimmel SC, Levein RI, Martiniuk F, Wiessman G. A mechanism for the antiinflammatory effects of corticosteroids: the glucocorticoid receptor regulates leukocyte adhesion molecule 1. Proc Natl Acad Sci USA 1992; 89: 9991.

11. Katori M, Oda T, Nagai K. A site of action for dexamethasone on extravasation in the microcirculation. Agents and Actions 1992; 29: 24.

12. Tamashiro WMSC, Taveres-Murta BM, Cunha FQ, Roque-Barreira MC, Nogueira RM, Ferreira SH Neutrophil recruitment inhibitory factor: a possible candidate for a novel cytokine. Mediators of Inflammation 1992; 1: 2.

13. Espevik T, Nissen-Mayer J. A highly sensitive cell line, WEHI 164 clone 13 , for measuring citotoxic factor/tumor necrosis factor from human monocytes. JIm munol Methods 1986; 95: 99.

14. Souza GEP, Ferreira SH Blockade by antimacrophage serum of the migration of PMN neutrophils into inflamed peritoneal cavity. Agents and Actions 1985; 17: 97.

15. Hartree EF. Determination of protein: a modification of the Lowry method that gives a linear photometric response. Anal Biochem 1972; 48: 422.

16. Rocha N, Ferreira SH. Restoration by levamisole of endotoxin inhibited neutrophil migration, oedema and increased vascular permeability induced by carrageenin. Eur J Pharm acol 1986; 122: 87.

17. Cunha FQ, Souza GEP, Souza CAM, Cerqueira BCS, Ferreira SH In vivo blockage of neutrophil migration by LPS is mimicked by a factor released from LPS-stimulated macrophages. Br J Clin Pharm acol 1989; 36: 485 .

18. Cunha FQ, Souza GEP, Ferreira SH Macrophages stimulated with lipopolysaccharide released a selective neutrophil chemotactic factor: an in vivo demonstration. Brazili an J Med Biol Res 1986; 19: 775.

19. Souza GEP, Cunha FQ, Mello R, Ferreira SH Neutrophil migration induced by inflammatory stimuli is reduced by macrophage depletion. Agents and Actions 1988; 4: 377.

20. Lukacs NW, Strieter RM, Chensue SW, Widmer M, Kunkel SL. TNF- $\alpha$ mediates recruitment of neutrophils and eosinophils during airway inflammation. J Immunol 1995; 154: 5411.

21. Arya SK, Wong-Staal F, Gallo RC. Dexamethasone-mediated inhibition of human $\mathrm{T}$ cell growth factor and gamma-interferon messenger RNA. I Immunol 1984; 133: 273.

22. Culppeper J, Lee F. Regulation of IL-3 expression by glucocorticoids in cloned murine T lymphocytes. J Im munol 1985; 135: 3191. 
23. Culppeper J, Lee F Glucocorticoid regulation of lymphokine production by murine T lymphocytes. Lymphokines 1987; 13: 275.

24. Lew W, Oppenheim JJ, Matsushima K. Analysis of the suppression of IL$1 \beta$ production in human peripheral blood mononuclear adherent cells by a glucocorticoid hormone. Im munology 1988; 140: 1895.

25. Lee SW, Tsou AP, Chan H, Thomas J, Petrie K, Eugui EM, Allison AC Glucocorticoids selectively inhibit the transcription of the interleukin $1 \beta$ gene and decrease the stability of interleukin $1 \beta$ mRNA. Proc Natl Acad Sci USA 1988; 85: 1204.

26. Kern JA, Lamb RJ, Reed JC, Danielle RP, Owell PC. Dexamethasone inhibition of interleukin 1 beta production by human monocytes; post transcriptional mechanisms. J Clin Invest 1988; 81: 237.

27. Nishida T, Nakai S, Kawakami T, Aihara K, Nishino N, Hirai Y. Dexamethasone regulation of the expression of cytokine mRNA induced by interleukin-1 in the astrocytoma cell line U373MG. FEBS Lett 1989; 243: 25.

28. Mukaida N, Gusella GL, Kasahara T, Ko Y, Zachariae COC, Kawai T, Matsushima K. Molecular analysis of the inhibition of interleukin-8 production by dexamethasone in human fibrosarcoma cell line. Immunology 1992; 75: 674.

29. Beutler B, Krochin N, Milsark IW, Luedke C, Cerami A. Control of cachectin (tumor necrosis factor) synthesis: mechanisms of endotoxin resistance. Science (Wash DC) 1986; 232: 977.
30. Mukaida N, Zachariae COC, Gusella GL, Matsushima K. Dexamethasone inhibits the induction of monocyte chemotactic-activating factor production by IL-1 or tumor necrosis factor. J Immunol 1991; 146: 1212.

31. Forsyth KD, Talbot V. Role of glucocorticoids in neutrophil and endothelial adhesion molecule expression and function. Mediators of Inflam mation 1992; 1: 101.

32. Oda T, Katori M. Inhibition site of dexamethasone on extravasation of polymorphonuclear leukocytes in the hamster cheek pouch microcirculation. J Leukocyte Biol 1992; 52: 337.

33. Dias-Baruffi M, Roque-Barreira MC, Gunha FQ, Ferreira SH Biological characterization of purified macrophage derived neutrophil chemotactic factor. Mediators of Inflammation 1995; 4: 263.

ACKNOWLEDGEMENTS. This work was supported by grants from Fundação de Amparo à Pesquisa do Estado de São Paulo (FAPESP) and from Fundação de Apoio ao Ensino e Pesquisa da UNICAMP (FAEP) to W.M.S.C.T.

\section{Received 20 November 1996;} accepted 26 November 1996 


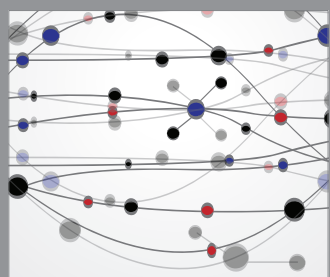

The Scientific World Journal
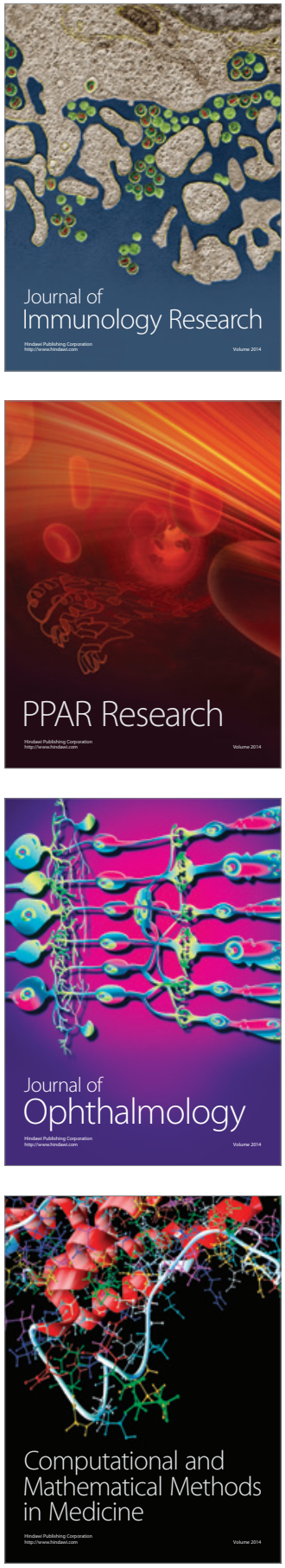

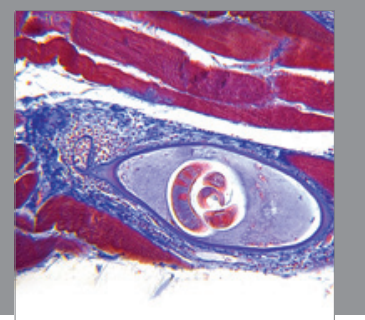

Gastroenterology

Research and Practice
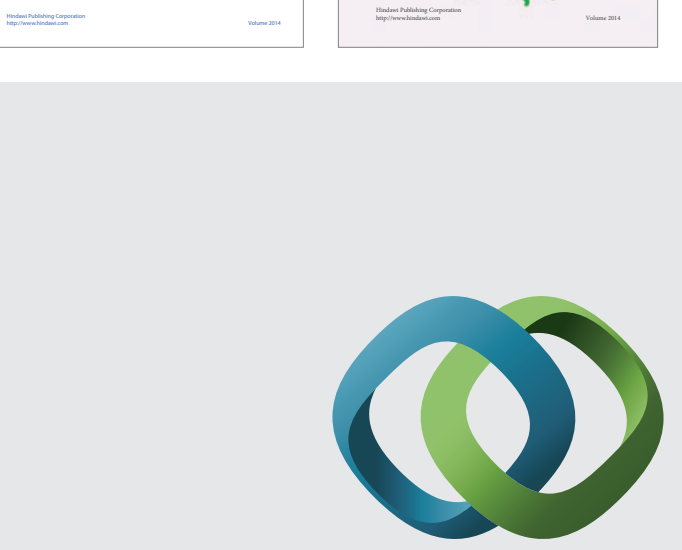

\section{Hindawi}

Submit your manuscripts at

http://www.hindawi.com
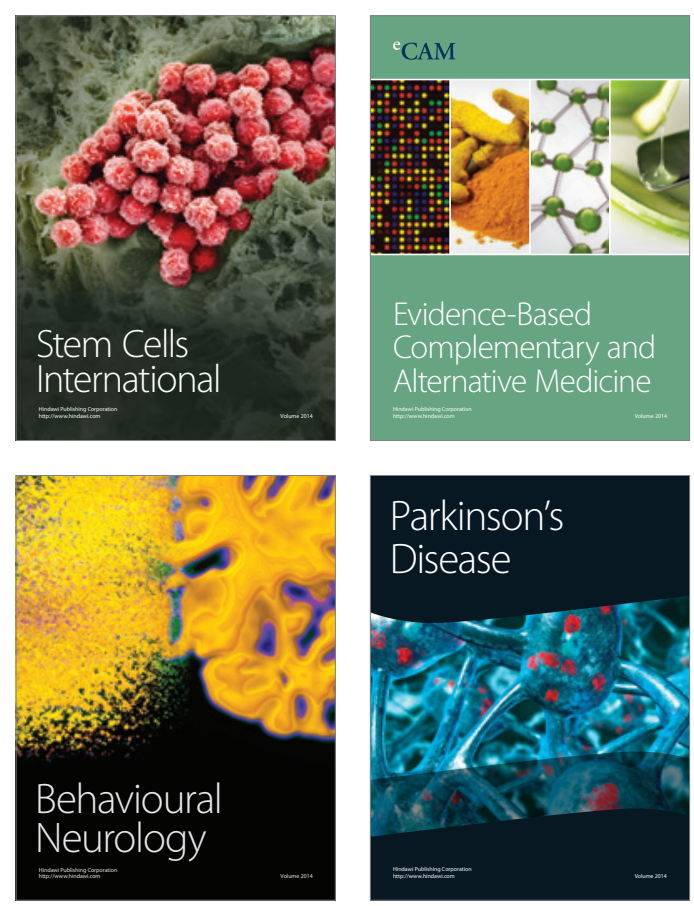

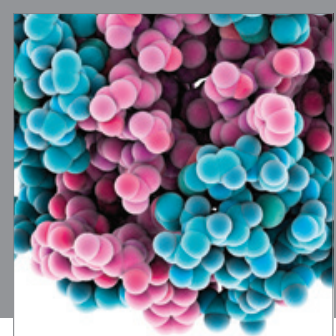

Journal of
Diabetes Research

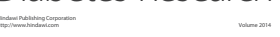

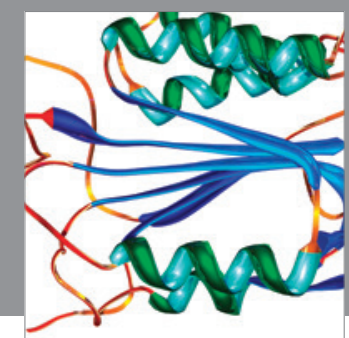

Disease Markers
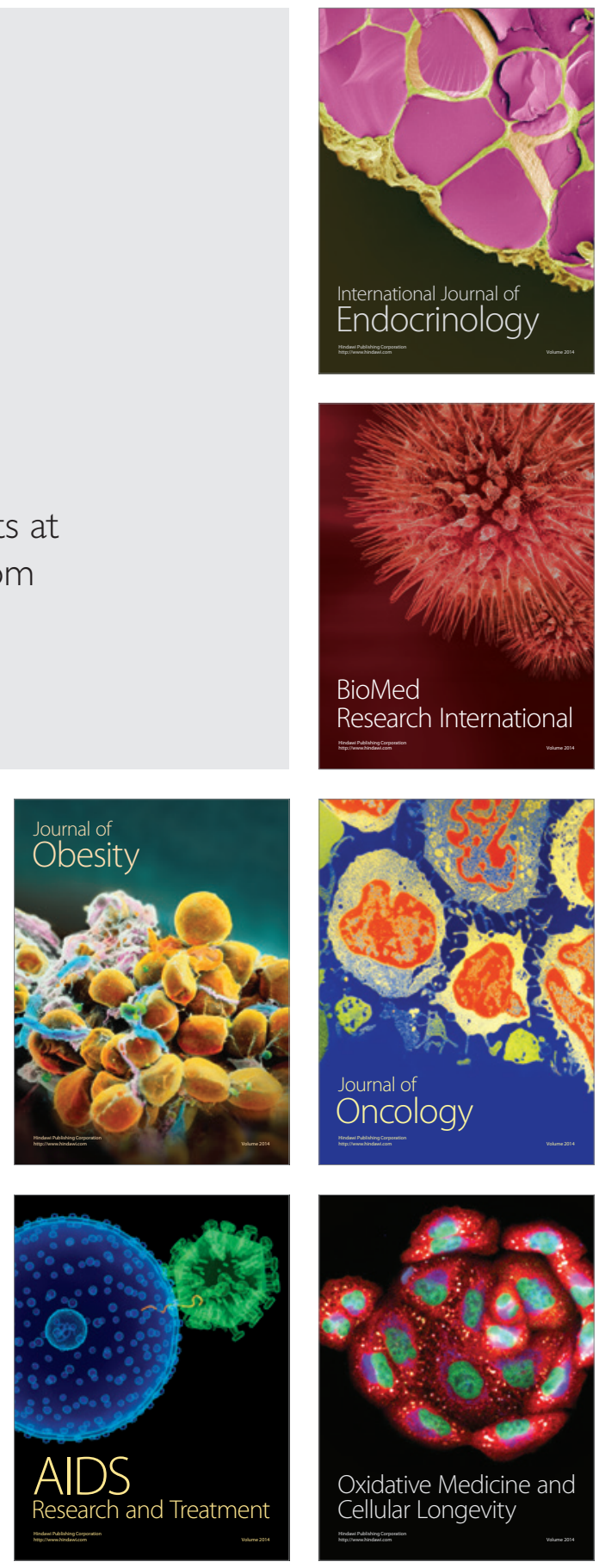